Canaceted with thin point, I should not aroid reference to the vlue of the horisontal position in such a case as that described by Bir Georgo Ieforre, and quoted at length in a previous part of this communication. I mean a case where such an enlarged condition of the reins exists that these ressels become, in the erect posture of the body, large receptacles of slowly circulating or almost stagnant blood. I have already fully explained that the value of recumbency arises, in these instances, purely from the mochrnical fact that the arrested blood finds an easy passage to the centre of the body when the effects of gravity are removed.

v. An inference can be drawn from the experiments as to the manner in which syncope is produced after operutions in which a large quantity of watery fluid is rapidly extracted from the system. It will be seen that syncope after the operation of paracentesis abdominis arises merely from the rush of blood into the abdominal veins previously compressed by the fluid pressure around them; and that, next to applying a due amount of equal external pressure over the abdomen during this operation, there is no practical fact of so much importance as laying the body in the horizontal line.

I have thus endearoured to illustrate several points connected with the effect of the horizontal position in syncope. I have tried to show that there is no direct relationship between the functions of the nerrous system and the action of the heart. I have shown by experiment that the blood is the only stimulus to the heart's motion, and have done my best to prore that the good effects of recumbency rest in erery case on mechanical causes alone. Lastly, I have made an attempt to turn the experiments and the opinions doduced from them to some practical account in the treatment of disease-a course which, if my own feelings on such matters are correct, ought to be pursued by every physiological inquirer who ventures on the important step of sacrificing inferior animals for the purpose of investigating the intricate laws of life.

12 Hinde Street, Manchester Square, October 1854.

\section{CASE OF EMPYEMA SUCCESSFULLY TREATED BY THORACENTESIS AND IODINE INJECTION.}

By JOHN WINDSOR, F.R.C.S., Senior Surgeon to the Manchester Eye Hospital.

[Read at the Anniversary Meeting of the Provincial Medical and Surgical Association, at Manchester, Sept. 14th 1854.]

Ix the fifth volume of the Transactions of the Association, I related some "facts illustrative of the effects of chronic pleuritis ;" on the present occasion, I purpose describing rather briefly a case which has recently come under my observation and treatment, and which may be considered as supplementary to the paper above alluded to.

CAsE. Thomas Norris, aged forty-five years, an operative spinner, residing at No. 11, Butler Street, Oldham Road, Manchester, called at my house to consult me on the 7 th, and again on the 13th of April 1854. He presented a pale sickly aspect, but in other respects apparently a well-built frame. He said that when in bed he could lie only on his left side. He had a troublesome husky almost dry cough, but had never spat any blood. His pulse was 108 in a minute, small, and rather indistinct, especially in the right wrist. His tongue was covered with a whitish, or rather, brownish-white fur. He complained of soreness, and of what he called "a mass of pain," on the left side. By auscultation no respiration could be heard in the left lung, except anteriorly somewhat indistinctly just below the clavicle, and slightly also opposite posteriorly. The left side was erery where dull on percussion. On measuring the two sides of the chest, there was little difference (only from a quarter to half an inch more in the left) in their width; but the right ribs were seen to move in respiration rather mest thin the left, and the intercostal spaces were more visible on the right side. The pulsations of the heart were not audible in the nsual place, but were very distinctly heard on the right side, especially near the right nipple.

About last Whitsuntide he first began to feel out of health, with cough, dyspncea, and uneasiness of his left side; these symptoms never left him since, although varying at times in severity. He did notremember having ever had any very severe pleuritic stitches. Excepting for three weeks at the commencement of his complaint, he had continued his occupation to within a week of the time when he consulted me. He had used very little medicine, except homoopathic, during the first three weeks of his illness.

I prescribed for him a cough mixture, containing oxymel of squills and poppy syrup, with a little tincture of digitalis, ipecacuanha wine, and antimonial wine; also some alterative aperient pills, of equal parts of compound extract of colocynth and blue pill.

April 14th. Accompanied by my son, Thomas Windsor, and pupils C. Jullott and N. Pickford, I visited him for the first time at his own house. He had passed a bad night from dypsnoca, pectoral oppression, and occasional cough, with slight mucous expectoration. The pulse was 108, small, and feeble ; in the right wrist scarcely perceptible. He said he was totally deroid of appetite, and felt great prostration of strength. Being satisfied, by the preceding and a further exploration now of the chest, of the probable existence of fluid in the left pleural cavity (an opinion in which my son fully concurred), I passed a grooved exploring needle along the upper surface of the seventh rib, when a quantity of turbid or somewhat puriform fluid issued. I, therefore, after elevating the integuments about an inch upwards, so as to have afterwards a sort of valvular covering to the aperture made into the chest, passed in a small trocar also just along the upper surface of the seventh rib. The fluid passed out freely through the carnula, until about fifty-two ounces were withdrawn. During the period of its evacuation, the thumb was placed for a short period four or five times on the mouth of the canula, so that the pleural cavity might not be too suddenly emptied. The punctured part was simply corered with a little lint, adhesive plaster, and a few light turns of bandage. His breathing and the pectoral oppression seemed relieved by the operation; but he was troubled just afterwards by a rather severe attack of coughing, with slight mucous expectoration, which went off after drinking a little tea. The pulse was now 66

When I visited him again in the evening, he expressed himself as being pretty easy altogether, and had not been troubled with cough since the morning.

April 16 th. His pulse, which yesterday was 96 , was this day 88 , and fuller. He was now in good spirits, and had scarcely any cough. His appetite was pretty good; he had no pain ; his bowels were regular, and the urine free. His respiration was somewhat improved on the left side both anteriorly and posteriorly, but it was still scarcely audible below the nipple, or in the opposite portion of the chest behind. There was corresponding dulness on percussion. The sounds of the heart were now heard most distinctly under the middle of the sternum. Last night he was able to sleep pretty well on his right side.

April 19th. Since last report is had gone on favourably. The pulse was about 84 ; the tongrie was pretty clean. He had a little cough, occasionally with slight mucous expectoration. There was no particular pain; his appetite was fair; the bowels wcre regular, and the urine was apparently natural in appearance and quantity. He slept tolerably well on either side. Percussion and auscultation afforded about the same signs as before.

April 25th. He was much the same. For the last fer days he had walked out several times. The mixture was continued, and the pill to be taken when required.

May 3rd. For some days he had not been so well as to his breathing, cough, and decubitus, although his pulse, appetite, etc., were pretty good. I thought it best therefore again to withdraw the fluid, which on this occasion smounted only to about thirty ounces, but was of the same 
cmp-purulent appearanoe as before. He bore the operation quite well, and folt rolief from it. I had proviously examined his chest, and found the sme signs elicited by auscaltation and percussion; the heart beating most distinctly between the sternum and right nipple. I was never able to detect any mgophony.

Mey 5th. He had felt better again since the operation; his breathing being easier, the pulse was 88 , the appetite and sleep good. His urine had been very copious on the day after it and since; the bowels were regular.

May 12th. He continued much in the same state.

May 17th. There was no particular change. Percussion and auscultation of the chest throughout elicited nothing new. He continued his mixture, and a pill occasionally.

May 30th. For the last few days his breathing had become worse, with less ability of lying on the right side, and more cough, with scarcely any expectoration; there was also more oppression about the chest, and he had not quite his usual good appetite, yet he had walked out generally an hour or two each diy. The pulse was about 84 . The signs from percussion and auscultation were about the same.

On this day I operated for the third time, and drew off from near the same part of the chest two pints and a half, or forty ounces, of sero-purulent fluid, but certainly less puriform than on the two former occasion. Immediately afterwards I injected five ounces of the following solution:

B Iodinii $3 i$,

Potassii iodidi zi.j,

Spiritús rectificati ${ }_{j} i$

Aquæ puræ ऊेv. M.

After retaining it in the chest a short time, and moving him a little about to bring the injection better into contact with the pleural membrane, I withdrew my thumb from the canula, when about an ounce of the injection returned through it, the rest remaining in the cavity. On this occasion I was assisted by my son and two pupils; and another gentleman was also present.

He bore the operation again very well, but a troublesome dry shaking cough almost immediately succeeded, as after the first thoracentesis; it was, however, again soon relieved by taking a little warm tea, and he remained pretty easy the rest of the day.

May 3lst. The pulse was 96 ; the tongue was whitish, and he complained of an unpleasant taste or sensation about his mouth and throat; his appetite was indifferent; the cough was troublesome. He had not much sleep last night. The bowels had not been moved since the previous morning. He complained of more uneasiness in the chest, and of a sort of general soreness over the left side, probably referrible to the action of the iodine injection. He lay at present most easily on his back, or slightly towards the left side. A large quantity of urine, about four or five pints, was passed in the afternoon after the operation, as happened somewhat similarly after the two former tappings. He was directed to continue the mixture, and occasionally the pills.

June lst. He felt better this morning. The pulse was 84 , the soreness of the chest was going off, and he could lie on either side, but neither his sleep nor his appetite were jet good.

Sune 7th. He now had begun to go out of doors, and walked a good deal daily, of which exercise he was very fond. The pulse was 92; the bowels were regular; the unpleasant taste of the mouth was gone; the appetite and sleep were better; the cough still continued, with occasionally a little mucous expectoration.

As stated above, he had a disagreeable taste in his mouth for some days after the operation, probably from the presence of iodine in the secretions. It may be added, also, that on testing the urine on the third day after the operation with liquid starch and sulphuric acid, it still afforded distinct violet tinge.

Auscultation and percuseion indicated nothing new, excopt that there was a very resonant space between the left nipple and the sternum.
June 15th. Since last report he had continued gaing an well. He now lay quite as easily on the right as on the left side; he walked out a good deal, almost daily. He had still some cough, for which he was prescribed a linctus with morphis murias; and was ordered to continue his former medicine.

June 20th. His cough was now less frequent and oasier, with a little mucous expectoration, and his breathing was pretty easy, even under exercise out of doors; he had no pain, and scarcely any feeling of soreness of the left side, and he could lie in any position. The feeling of "swilling", as he called it, or gravitation of fluid from one side to the other, which he used to experience in turning in bed, had now gone off.

July 1st. IIe said that he now felt free from complaint, having no cough, pain, or soreness of the chest. He purposed going into Cheshire for about a fortnight.

On examining the chest, I found the heart beating now most distinctly nearly in its natural situation, or just to the right of the left nipple. On desiring him to breathe rather deeply, the left lung seemed to admit air nearly throughout, although the respiratory sound was not so loud as on the other side. The resonance on percussion now also approximated to that on the right, but the percussion was dullish in the situation of the heart, where it had lately been resonant. The intercostal spaces had become about as distinct as on the other side.

July 20th. He called upon me after his return from the country, and said that, feeling well, he was about resuming his occupation.

Sept. 9th. I saw him again, and found him pretty well, and pursuing his occupation. There was yet little, if any, depression or contraction of the affected side; and he indeed complained of nothing, except a little weakness or aching about his shoulders occasionally, probably ascribable, at least in part, to the laborious nature of his employment.

Reucaks. In the preceding case, which seems to have terminated so satisfactorily, I was induced in the thind time of tapping him to add the use of an iodine injection, in consequence of reading a paper (pointed out to me by my son) published by Dr. F. A. Aran, physician to the La Pitié at Paris, in the Union Médicale (Nos. 97, 98, and 99), 1853, and also inserted in the Encyclographic des Sciences Mlédicales for October 1853. Dr. Aran there recapitulates in part what has been done, especially of late times, in regard to injection of the pleural cavity after thoracentesis in cases of effusion, in consequence of acute or chronic pleurisy. In such cases, as Dr. Aran remarks, patients often sink under exhausting hectic fever, as in phthisis pulmonalis; or from the formation of a pleurobronchial fistula, suffocation way occur by too great an accumulation of fluid in the bronchial passages; or sometimes, especially perhaps if air be admitted, from the fluid becoming vitiated, and thus poisoning, as it were, the blood. In some of these cases of fluid, generally seropurulent accumulation in the pleural cavity, it finds an exit by a sort of abscess forming in the parietes of the chest, as occurred in the case of Morris, mentioned in my former paper published in the fifth volume of the Transactions of this Association. Thus the pleural effusion may, when not re-absorbed spontaneously, be sometimes discharged by a communication with the corresponding lung and bronchial tubes; at others, by a communication with the external parietes of the thorax; or, indeed, by a combination of both these modes. Of this last form, apparently, I attended a case this year in consultation with Mr. Robb. It occurred in a Mrs. Kitchen, of Chester Road, Hulme, aged about 60, and the mother of a large family. Mr. Robb had attended her a considerable time before I saw her. Besides expectorating a good deal of puriform fluid, occasionally tinged with blood, subsequent to an attack of pleuropneumonia probably of the right side, two abscesses formed soon after I saw her, on the lower part of the right side, one a few weeks after the other. They were both opened, and, especially the first one, gare exit to a considerable quantity of pus, increaced during expiration and coughings 
Bu beenme gradually exhausted, and did not long survive the formation of the second abscess. Unfortunately a post mertem examination could not be obtained. In this case there was great dullness on percussion over a considerable portion of the right side, and only slight respiratory murmur could be heard anteriorly at the upper part of the chest, in the subclavicular space, and posteriorly near the spine.

Dr. Aran cites two cases of thoracentesis for acute (purulent) pleurisy by Dr. Trousseau, but both terminated fatally at last, which was not remarkable, as they were complicated with other serious affections. Dr. Trousseau had also operated four times for chronic purulent pleurisies, but all terminated fatally at no distant period.

From the pyogenic disposition of the pleural membrane, and therefore the great disposition to relapse after thoracentesis, it becomes a question, and a very momentous one in preventing a fatal termination, so common in this disease, how far we may be able to counteract a recurrence of the effusion by the use of injections, and most effectively perhaps by the use of iodine ones. $M$. Boinet has referred to three cases where they have been employed, once by himself, once by M. Boudant, and once by M. Massiani. In the last case a cure was effected in three months, but with considerable deformity of the chest ensuing, along with depression of the corresponding shoulder, and lateral inclination of the vertebral column. It is well known since the researches of Laennec, * that this change may follow a natural cure, and was indeed referred to in my former paper, as occurring in Mr. Burton's patient, Mr. Liversedge, the artist. In M. Boudant's case, a cure was effected in six months, but with some sinking of the ribs, and slight devintion of the sternum. In M. Boinet's case, a cure was effected in four months, but with flattening also of the ribs. In al these three cases, air was admitted into the chest, which probably modified injuriously the character of the fluid. If this admission of air be prevented, either totally or almost so, by making a valrular opening, as I did in each of the three operations on Norris, a speedier cure may be expected, with less subsequent contraction of the chest, probably from the readier adhesion of the opposing membranes, and consequent obliteration of the pleural cavity.

In two cases operated on by Dr. Aran also in this way, one of acute and the other of chronic pleurisy, the former terminated fatally by the supervention of subacute peritonitis; but the latter, occurring in a locksmith, aged 24 , and of fifteen to eighteen months' duration previous to treatment, terminated successfully after a single iodine injection.

When we consider the result of the treatment of these six cases of pleuritic effusion by iodine injection, five out of the six being successful, and that the other would not improbably have been so also, had it not become complicated with another affection,-it must, I think, be conceded that it is one offering considerable advantages.

I am not aware of any other case besides the one related in this paper having been yet treated similarly in this country ; but from the satisfactory result in this one instance, conjoined to those of a few similarly treated abroad, I think we are encouraged to give it a further trial in cases apparently adapted for it. Such cases seem to be those of chronic uncomplicated pleuritic effusion. Similar success could scarcely be expected when this empyema is the result of a vomica or vomices bursting into the pleural cavity, or where the effused fluid has been suffered to remain so long as to form external communication through the parietes of the chest, or where both these states are coexistent. Of all these forms and complications, I doubt not, most have seen examples; and instances of them are referred to both in this and in the former paper. However, even in such circumstances, where a permanent cure is unattainable, great temporary relief to the oppression and

- Perhaps I may be permitted to state, that In the year 1822, I had an oportunity of accompanying Leennec in the wards of the Hopital Necker, of ortunity of accompanying Laennec in the wards of the Hopers and then introdncing into this part of the country their ves: one was for my old friend introdecing into this part of the country their nee: one ras dyspnces is often afionded by the operation of thoracentecia The process itself of withdrawing the fluid by the use of the trocar and canula alone, without any previous incision or dissection, is one of extreme simplicity; and, though I have now performed it mauy times, no unpleasant accident has ever occurred.

Manchester, Soptember 1854.

\section{CASE OF HYDROCEPHALUS IN A CHILD, SIX MONTHS OLD, IN WHICH THE HEAD} WAS TAPPED EIGHT TIMES.

By J. D. BROWN, Esq.

A cHILD, six months old, with chronic hydrocephalus, wres placed under my care on July 10th, 1852. I enclosed the head with straps of adhesive plaster, and persevered in this plan for some time. No good effects were produced. I now proposed tapping, to which the parents consented. Mr. Rowe was called into consultation, and assisted.

August 6th. We removed six ounces of serum. The child became a little sick and faint.

August 7 th. The child was apparently much improved; it looked more intelligent, and took greater notice of the nurse. The head was tightly strapped up.

August 18th. The head was as large as ever. It was tapped to six ounces, with the same results.

September 6th. The head was larger than it had been at all; and it was tapped to eleren ounces, with the same results as on the previous occasions.

September 28th. The head was again larger; and twenty ounces of fluid were removed by tapping, with the same results.

October 8th. The head was tapped to eleven ounces.

October 18th. Tapping was performed, and sixteen ounces of fluid were removed.

October 25th. Twelve ounces of fluid were withdrawn.

October 30th. We now abandoned tapping as useless, and inserted a seton of silk through the membranes of the brain, running it along the interior for an inch before bringing it out. No immediate result was produced; but a great quantity of serum flowed from the orifices through which the seton passed. At the end of twelve hours, there was no change. At the end of twenty-four hours, there were vomiting, restlessness, and expressions of pain and distress. In thirty-six hours, there appeared twitching of the muscles and startings, bordering on convulsions. In forty-ejght hours from the introduction of the seton, the child refused his food. Moaning and approaching stupor were now observed. The seton was now removed; and these symptoms gave way in a day or two. The head was by this time much decreased in size, and continued so for several days.

We now flattered ourselres with hopes of a cure; but in another day or two, cvident signs of secretion manifested themselves, and at the end of twelve days we tapped again, and again the fluid collected. We now gave up all hope, and allowed the disease to take its course. The head attained a frightful size; and the child died.

Examination of the Body. A large washhand basin full of serum was taken out of the brain. The containing sac was formed by the brain, which was completely unfolded, and so stretched, that it was no thicker than the dura mater. This fact, in our opinion, accounted for the failure of the treatment. IIad the water been contained in the membranes instead of in the rentricles, there would have been a better chance of success.

I would never hesitate to make similar attempts at a cure, with the hopes of the membranes being the investing envelope of the water. In such cases, a happy termination might be expected.

Haverforàwest, October 1854 